\title{
A TOOL FOR PROMOTING INTRINSIC MOTIVATION IN TEAMS: A CASE STUDY OF PARTICIPANTS' MOTIVATION DURING A DESIGN PROJECT
}

\author{
Nina Olkowska JACOBSEN and Arild BERG \\ OsloMet - Oslo Metropolitan University
}

\begin{abstract}
Intrinsic motivation is a prerequisite for creativity. Research requires more studies on the prerequisites for intrinsic motivation where design thinking is used as an approach to develop a tool. In this case study, such a tool was developed to help project managers understand what creates intrinsic motivation in team members of a student project. The research question was: How can product design help project managers prevent demotivation in project work? Qualitative methods were used to gain an in-depth understanding of what strengthens, or weakens, intrinsic motivation. Data was collected from a student's insider perspective of daily documentation of a creative project, 'Design Studio', with participants from three levels of education, where the third year students were leaders in a Department of Product Design. Inspired by a 'grounded theory' approach, the analysis process pointed to three categories in which factors were identified that seemed to strengthen motivation. The three factors were commitment, sense of mastery and productivity. The discussion revolves around how such a product design-based tool can help project managers map what strengthens or weakens commitment, sense of mastery and productivity among team members. The conclusion encourages project managers to use evaluation during the process, with the intention of mapping when and how the three factors were strengthened or weakened, and logging the data using the tool.
\end{abstract}

Keywords: Adaptability, engagement, education, management, collaboration

\section{INTRODUCTION: LEADERSHIP AND CREATIVITY}

Studies have been conducted that address how motivation affects creativity. An article on leadership behaviour and the work environment for creativity [1] and a model for creativity and innovation developed by Teresa M. Amabile [2] both point out that inner motivation is a prerequisite for creativity to unfold in project work. Internal motivation occurs when the motivation is driven by interest, pleasure and the challenges of the work tasks [3]. Some external motivational factors can be seen as important when it comes to creativity [2]. External motivation is driven by external sources that are not directly related to the task [3]. Objectives, reward systems, evaluations and pressure are aspects of the creative work environment that are considered external motivational factors [2]. It has been discussed whether the external motivational factors can be used with a sensible approach to promote creativity. In 2016, Amabile published an article, in collaboration with Michael G. Pratt, in which new theories were developed within the same framework. The research built on the theories that were published in 1988 [3] and generated new knowledge in the field. Theories stating that external motivational factors can have an effect on creativity were not rejected, though it was emphasised that a strong inner motivation for a task is absolutely decisive for how creativity takes place in a project [3]. This background provides the research question: How can product design help project managers prevent demotivation in project work? Relevant sub-questions that are taken into account to answer the research question are: 1) What factors strengthen or weaken motivation among team members in the context of project work? 2) In what way can project managers facilitate motivation among team members? The study searches for answers to this to form a holistic picture of specific ways in which project managers can facilitate motivation among team members. 


\subsection{Relevance of this study}

The abovementioned studies provide an understanding of how motivation can have an impact on creativity, and that intrinsic motivation is a prerequisite for creativity. However, they provide little information about how the inner motivation arises. There is potential in researching how motivation can be facilitated, and how activities that are not controlled by inner motivation can be facilitated. The study is considered relevant to project managers working in teams.

\subsection{In what way is design competence important in this discussion?}

'Design thinking' methods represent an approach that can be used in connection with problem solving in product design. The approach is a people-oriented way of working, innovating, and developing, and involves ways of solving problems that can provide valuable benefits [4]. In this study, the method was used to develop a tool which project managers can use to form an understanding of what creates motivation in their team. The analysis of the database provided insights that were used to prepare the tool.

\section{METHODS: A QUALITATIVE CASE STUDY}

\subsection{Collection of data}

Qualitative research was used through case study [5]. The purpose was to gain an in-depth understanding of the factors that strengthen or weaken, motivation among team members in the context of project work. The research is limited to a project that took place in the fall of 2019. The team consisted of product design students, and the project goal was to develop sustainable packaging. The project was one of several projects that were carried out in connection with Project Design Office, an annual collaboration project involving first-, second- and third-year students at the Department of Product Design at Oslo Metropolitan University. The third year students are project managers, and one of the learning objectives is to experience the leadership role. The project used in this study had 11 participants: four leaders and seven team members from the first- and second-year cohorts. The study was directed by source-oriented research [5], and the approach facilitated the use of existing information derived from documentation of practice.

\subsection{Analysis of data}

Analysis of the empirical data in the case was inspired by grounded theory [5]. In the context of this study, the method was simplified and limited to dealing only with data collection based on documentation and reports from the current project. During the analysis of the documentation, searches were conducted for factors that strengthened or weakened the inner motivation of the team members. These were synthesised into three categories, and three factors, and formed the basis for the development of a tool that shows project managers how they can facilitate motivation among their team members.

\section{DATA COLLECTION: THE PROJECT AND THE PARTICIPANTS' MOTIVATION}

The source-oriented research was based on a database that originated in one systematic documentation of each working day during the three weeks of the project. The documentation was performed by the leaders and consisted of an evaluation of the working day. The daily evaluation was made at the end of the day, in plenary, with both the leaders and the team members present. The evaluation was based on the following points: 1) What was done today? 2) What worked well? 3) What could have worked better? 4) The leaders' own reflections on how the feedback could be used for planning the subsequent working days. The changes and adjustments the leaders made based on the feedback during the evaluation, and how they played out in practice, were also recorded in the document. The documentation will later be referred to as the 'evaluation'. The document comprises a total of 17 A4 pages. The database was anonymised for privacy reasons and was not published. In the reference list, it is referred to as 'Dynamic Project Leadership BAPD3000, Oslo Metropolitan University 2019' [6] with a link to the course, including information and contact details for the course leader. The database was valid for the entire analysis. 


\section{CATEGORISED DOCUMENTATIONS FROM THE PROJECT}

In the analysis process, the connection between the various activities and tasks, and whether team members experienced motivation were interpreted inspired from grounded theory methods. The changes that were made to facilitate and adapt activities and work tasks during the process, and the results, were also taken into account during the analysis process. The analysis mapped patterns that indicated situations that created both motivation and demotivation.

\subsection{Category 1: The use of warm-up exercises}

In general, various forms of exercises and games were used, independent of the project objective. The purpose was to prepare the team members for the subsequent tasks, and the preparatory exercises had a clear connection with the work tasks. As a preparatory exercise for idea generation, the team members played, for example, a form of Chinese whispers, a game that basically involves visualising different words and explaining a word visualised by one's opponent. The preparatory exercises had a very positive effect on the subsequent work that was performed that day, according to the evaluation. The exercises resulted in a low threshold for working on idea generation, and generally created productivity and engagement. On days when no preparatory exercises were done, the team members found it difficult to get started on their tasks. As a result, several team members experienced low productivity, a low sense of mastery and demotivation.

\subsection{Category 2: Dynamic work}

At some stages in the project, some team members felt they had nothing to contribute. The evaluation of those days show that this created demotivation and weakened the team members' sense of mastery. The leaders' initiative was to start the working day by defining different focus areas, such as: 1) work on a graphic profile for the packaging, and 2) create prototypes. The team participants had to choose which work tasks they wanted to take on and collaborated in small groups on performing them. They were free to change work tasks during the day. The flexibility in the working day was defined as 'dynamic work'. An example shows team participant 1 starting work on the graphic profile, but during the working day choosing to assist the group that was working on the prototype. The evaluation shows that this created commitment and strengthened motivation. It also proved to have a positive impact on the ideas that were developed when the team members could build on each other's ideas to a greater extent.

\subsection{Category 3: Demotivating with schematic tools}

On the first working day of the design process, the team used schematic tools. The activity was led by the leaders and was done in plenary. There was made agreements on goals and criteria for the project. The purpose was to form a common basis for the project, and the tools were carefully introduced to the team members. The evaluation of the day shows that the team members saw the value in the tools and understood the reason for the tools being used. At the same time, it gave an insight into what the team members experienced as demotivating when using the schematic tools. The work was described as boring and monotonous, and concentration and interest among some team members in implementing it were weakened. One of the feedback comments read as follows: 'Filling out forms is not always fun, but it has to be done'.

\subsection{The three factors that facilitate motivation}

In the three categories, three factors emerge that strengthen motivation. Situations where motivation was strengthened showed clear connections with the work tasks being engaging, that the team members experienced a sense of mastery and that the working days were productive. The use of preparatory exercises proved to be an appropriate use of the working day, to create productivity in the working day. By opening up for dynamic work, team members were given the opportunity to assist with work tasks to which they themselves felt that could contribute most. This created commitment and strengthened their sense of mastery. In the analysis, three categories were identified, as well as three factors that played out in the categories. The categories and factors seemed to be important in strengthening inner motivation. 


\section{DISCUSSIONS: USING A TOOL TO MAP MOTIVATION}

\subsection{Evaluation}

As a project manager, it can be useful to use daily evaluations where input from team members is taken into account. The data shows that the feedback gave the leaders insight into, and an understanding of, how the team members experienced the work on the project. In this way, the leaders got to know their team, and they got the opportunity to facilitate and adapt activities, depending on what the team members found motivating and demotivating. As shown in categories 1 and 2, motivation was strengthened after the adjustments were made. Using the feedback actively can give leaders an opportunity to facilitate motivation in their team.

\subsection{Going from 'this is what I need to do' to 'this is something I want to do'}

Establishing a common goal for a project is absolutely crucial to its success [7]. The goal of the project can be guided by an inner motivation in individuals, or from an external source [3]. The schematic tools used in the project were used under the auspices of the leaders, and the data shows that the team members considered it something they had to do (Section 5.3). One can therefore say that the activity was not controlled by the intrinsic motivation of the team members.

In cases where work tasks were not governed by intrinsic motivation, it may be appropriate to look at what weakened motivation. Drawing on inspiration from activities and tasks that have been shown to have a strengthening effect on inner motivation in other situations can be a way to facilitate inner motivation. Category 3 is an example of a task that weakened inner motivation. The reason was that the schematic tools did not engage the team. The data, on the other hand, shows that involvement occurred in those cases where preparatory exercises were used. Therefore, it may be appropriate to look at how preparatory exercises can be implemented in processes where the team uses schematic tools. For example, it might have been appropriate to implement play in connection with completing the schematic tools. A prerequisite for the leaders to be able to facilitate internal motivation in this way is that they are familiar with activities and work tasks in which the team members have demonstrated a genuine interest in implementing.

\subsection{Strengthening inner motivation with a tool}

The way in which the project managers adapted the activities based on the feedback through daily documentation of the evaluation indicates that the evaluation gave them an understanding of which factors characterised motivation within the team. Despite the fact that this form of documentation gave results in practice, the document can become confusing and difficult to map and apply in practice. Therefore, this study proposes a tool which may help managers establish a database of activities and tasks that can implemented where demotivation occurs (Figure 1). The tool is based on the three factors of intrinsic motivation that were defined in this study. The purpose of the tool is to give project managers the opportunity to experience and understand the situations where motivation was both strengthened and weakened. By using the database, they can use the activities and tasks that strengthened motivation, in those situations where inner motivation is weak. Using activities that have been motivating can help change attitudes towards activities which team members feel they need to do into something they want to do. Internal motivation occurs when activities and work tasks appeal to a genuine interest in implementing [3]. The mapping creates a database that indicates what has strengthened, or weakened, the engagement, the sense of mastery and the productivity. 


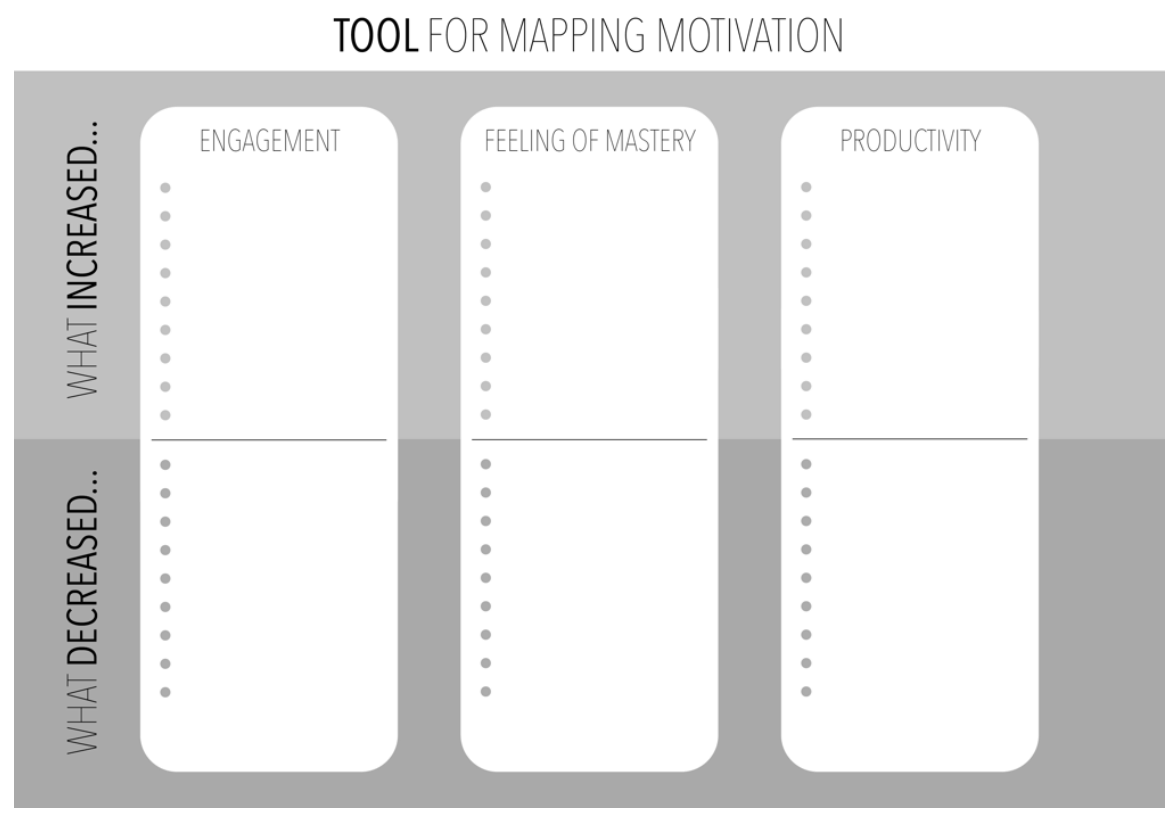

Figure 1. Proposed tool template for mapping motivation in teams. The mapping creates a data base that indicates what has strengthened, or weakened, the commitment, the feeling of mastery and the productivity.

\subsection{Limitations and assessments of the study}

In this case study, three factors were identified that strengthened motivation among the team members during a specific project. A tool was also developed that can be used to ensure motivation among team members. This study was limited to looking at what weakened or strengthened motivation among product design students during the specific project. The database was structured and informative and was a strength in this study. Nevertheless, it will be appropriate to study several teams and projects, both interdisciplinary teams and teams working on projects in other professions, to nuance the findings. In this connection, it is recommended to study how motivation unfolds to see whether findings are similar to or different from the findings of this study. The tool that was developed in this study should be developed and tested in various practices. The goal of the testing can include assessment of whether the tool is helpful to project managers, and whether using the tool helps strengthen inner motivation in cases where it was previously weakened.

\section{CONCLUSIONS: POTENTIAL AND FURTHER RESEARCH}

This study has sought to understand the factors that strengthen or weaken motivation among team members in the context of project work. The purpose was to give project managers guidance and a tool that can help them prevent demotivation among team members during project work. The study provided insight into situations where inner motivation occurs. The findings illustrate that it occurs when: 1) work tasks are engaging, 2) the team members experience a sense of mastery, and 3) the working days are productive. An important prerequisite for preventing demotivation is that project managers know their team members. It may be appropriate to make use of daily evaluation where team members are encouraged to provide input on how they experience their working. The database can be of valuable importance and absolutely essential to facilitating working days that create motivation among team members. Project managers are encouraged to map which activities and work tasks that create motivation, and to implement them in work situations where team members experience demotivation. Such a tool can help leaders analyse and change a situation considering whether motivation was strengthened or weakened based on the three factors. It remains to nuance the three factors by conducting similar studies of other projects, and by testing the tool in various practices.

\section{REFERENCES}

[1] Amabile T. M., Schatzela E. A., Monetaa G. B and Kramerb S. J. (2004). Leader behaviours and the work environment for creativity: Perceived leader support. The Leadership Quarterly, 2004 (15), 5-32. https://doi.org/10.1016/j.leaqua.2003.12.003. 
[2] Amabile, T. M. (1988). A model of creativity and innovation in organizations. Research in Organizational Behaviour.

[3] Amabile, T. M. and Pratt, M. G. (2016). The dynamic componential model of creativity and innovation in organizations: Making progress, making meaning. Research in Organizational Behaviour, 2016 (36), 157-183. https://doi.org/10.1016/j.riob.2016.10.001

[4] Aflatoony, L., Wakkary, R. and Neustaedter, C. (2018). Becoming a Design Thinker: Assessing the Learning Process of Students in a Secondary Level Design Thinking Course. International Journal of Art \& Design Education, 2018(37.3), 438-452. https://doi.org/10.1111/jade.12139

[5] Muratovski, G. (2016). Research for Designers. Sage.

[6] Dynamic Project Leadership BAPD3000, Oslo Metropolitan University 2019 https://student.oslomet.no/en/studier/-/studieinfo/emne/BAPD3000/2020/HØST.

[7] Aakre, D. J. and Scharning, S. H. (2016). Prosjekthåndboka: verktøykasse for kreative team. [The Project Handbook, a toolbox for creative teams]. Universitetsforlaget. 